\title{
GLUTAMATE AND ASPARTATE BINDING SITES ARE ENRICHED IN SYNAPTIC JUNCTIONS ISOLATED FROM RAT BRAIN ${ }^{1}$
}

\author{
A. C. FOSTER, E. E. MENA, G. E. FAGG, AND C. W. COTMAN
}

Department of Psychobiology, University of California, Irvine, California 92717

\begin{abstract}
The binding of the putative excitatory transmitters glutamate (Glu) and aspartate (Asp) was measured in various subcellular fractions in order to assess their degree of localization in synaptic junctions (SJs). For both ligands, specific binding levels increased in the order, whole particulate membranes-crude mitochondrial pellet membranes $\left(\mathrm{P}_{2}\right)$-synaptic plasma membranes (SPM), and were highly enriched in $\mathrm{SJ}$, with values approximately 9 times greater than the values in whole particulate membranes. The recovery of binding sites in SJs suggested that the majority of sites in SPMs were junctional in nature. Specific binding sites were found also in other subcellular fractions, such as microsomal membranes, "light" SPMs, and mitochondrial membranes. Sodium ions were able to stimulate the specific binding of both ligands (Asp > Glu), the magnitude of the effect between subcellular fractions being in the order, whole particulate membranes $>\mathrm{P}_{2}>\mathrm{SPM}$. This effect was absent in SJs. Calcium and magnesium ions also enhanced the binding (Glu > Asp) in the order, whole particulate membranes $\geq \mathrm{P}_{2} \geq \mathrm{SPM}>\mathrm{SJ}$. The results indicate that Glu and Asp binding sites have a specific synaptic localization and support a role for Glu and Asp receptors in synaptic transmission.
\end{abstract}

Evidence that glutamate (Glu) and aspartate (Asp) are the major excitatory transmitter candidates in the mammalian central nervous system (CNS) has arisen from a large number of electrophysiological and neurochemical studies (for reviews, see Snyder et al., 1973; Curtis and Johnston, 1974; Johnson, 1978; Watkins, 1978; Fagg and Lane, 1979; Cotman and Nadler, 1981). Although electrophysiological experiments have shown Glu and Asp receptors to be present on many types of neuron, those specifically at the postsynaptic junctional membrane have not been described and characterized. The receptors activated by iontophoretic application of acidic amino acids may be junctional, extra-junctional, or a mixture of both types. For example, at the invertebrate neuromuscular junction, where Glu is the major transmitter candidate (Usherwood, 1978), the junctional membrane has been shown to possess a high density of Glu receptors (Takeuchi and Takeuchi, 1964; Usherwood and Machili, 1968), although extra-junctional receptors are found also (Takeuchi and Onedera, 1975; Onedera and Takeuchi, 1980; Cull-Candy and Usherwood, 1973). In the mammalian CNS, previous studies with tritiated Glu and Asp have revealed high affinity membrane binding sites which have characteristics similar to those of the physi-

\footnotetext{
'This work was supported by fellowships from the North Atlantic Treaty Organization and the National Institutes of Health and by Grants NS 08957 and MH 19691 from the National Institutes of Health.
}

ological receptors for these amino acids (Roberts, 1974; Michaelis et al., 1974; Fiszer de Plazas and De Robertis, 1976; De Robertis and Fiszer de Plazas, 1976; Foster and Roberts, 1978; Baudry and Lynch, 1979a; Biziere et al., 1980; Roberts et al., 1980). In the present study, use has been made of ligand binding assays in conjunction with subcellular fractionation techniques to assess the junctional location of excitatory amino acid receptors.

Synaptic junctions (SJs) can be isolated from mammalian brain by subcellular fractionation techniques (Cotman and Taylor, 1972; Davis and Bloom, 1973; Cohen et al., 1975) and have been used to investigate the biochemical characteristics of the synapse (Cotman and Kelly, 1980). In a previous paper, we have described an enrichment of binding sites for the Glu analogue kainic acid in purified SJs (Foster et al., 1981). In the work reported here, we have measured the binding of Glu and Asp to SJs and other subcellular fractions from rat brain in order to determine whether receptors for the putative transmitters Glu and Asp are enriched in the junctional region. We also report the effects of sodium, calcium, and magnesium ions on the binding of Glu and Asp to different subcellular fractions.

\section{Materials and Methods}

Materials. L- $\left[{ }^{3} \mathrm{H}\right]$ Glutamate $(43.3 \mathrm{Ci} / \mathrm{mmol})$ and $\mathrm{L}$ $\left[{ }^{14} \mathrm{C}\right]$ glutamate $(282 \mathrm{mCi} / \mathrm{mmol})$ were purchased from New England Nuclear (Boston, MA), and L- $\left[{ }^{3} \mathrm{H}\right]$ aspartate $(9$ to $15 \mathrm{Ci} / \mathrm{mmol}$ ) was from Amersham Corp. (Ar- 
lington Heights, IL). 4-(2-Hydroxyethyl)-1-piperazineethanesulfonic acid (HEPES) was obtained from Calbiochem (La Jolla, CA), and all other chemicals and common laboratory reagents were purchased from Sigma (St. Louis, MO) or Mallinckrodt (St. Louis, MO).

Preparation of subcellular fractions and SJs. Subcellular fractions were prepared using a modification of the method described by Cotman and Taylor (1972). Briefly, Sprague-Dawley rats (12 to 20 per preparation), aged 30 to 60 days, were killed by cervical dislocation and the forebrain was removed and homogenized in an ice cold solution of $0.32 \mathrm{M}$ sucrose containing $0.05 \mathrm{~mm} \mathrm{CaCl} 2$ and $0.2 \mathrm{~mm} \mathrm{HEPES}^{2}$ (pH 7.4). A crude mitochondrial pellet was isolated and, after lysis in $0.2 \mathrm{~mm}$ HEPES containing $0.05 \mathrm{mM} \mathrm{CaCl}_{2}$ (pH 7.4) (Ca-water), a solution of $50 \mathrm{mg}$ of iodonitrotetrazolium violet (INT) and $1.3 \mathrm{gm}$ of sodium succinate in $0.2 \mathrm{M}$ phosphate buffer $(\mathrm{pH} 7.4$ ) was added. The suspension was incubated to $30^{\circ} \mathrm{C}$ followed by centrifugation at $50,000 \times g$ for $25 \mathrm{~min}$. The pellet $\left(\mathrm{P}_{2}\right.$-INT) was resuspended in Ca-water and $2 \mathrm{~m}$ sucrose was added to give a final sucrose concentration of $0.85 \mathrm{M}$. This was layered onto a discontinuous sucrose gradient, and after centrifugation to equilibrium, the following fractions were collected: myelin (floating on $0.85 \mathrm{M}$ sucrose), "light" synaptic plasma membranes (light-SPM) (0.85 M, $1.0 \mathrm{M}$ interface), synaptic plasma membranes (SPM) (1.0 $\mathrm{M}, 1.3 \mathrm{~m}$ interface), and mitochondria (pellet). The SPM fraction was diluted with Ca-water, centrifuged at $50,000 \times g$ for $20 \mathrm{~min}$, then resuspended, and twice the volume of a solution containing $0.4 \%$ Triton $\mathrm{X}-100,2 \mathrm{~mm}$ EDTA (ethylenediaminetetra-acetate) in $10 \mathrm{~mm}$ HEPES ( $\mathrm{pH} 7.2$ ) was added. This was layered over $1.0 \mathrm{M}$ sucrose, and after centrifugation, SJs were collected in the pellet. Microsomal $\left(\mathrm{P}_{3}\right)$ membranes were prepared from $\mathrm{S}_{2}$ by centrifugation at $17,000 \times g$ for $10 \mathrm{~min}$ to remove residual $\mathrm{P}_{2}$ components $\left(\mathrm{P}_{2}{ }^{\prime}\right)$, and the supernatant $\left(\mathrm{S}_{2}{ }^{\prime}\right)$ was centrifuged at $50,000 \times g$ for 60 min to obtain the $\mathrm{P}_{3}$ pellet. The entire procedure is summarized in Figure 1.

The fractions collected were: the original homogenate, crude mitochondrial pellet $\left(\mathrm{P}_{2}\right)$, microsomes $\left(\mathrm{P}_{3}\right)$, myelin, light-SPM, SPM, mitochondria, and SJs. The original homogenate was diluted with $0.2 \mathrm{~mm}$ HEPES $(\mathrm{pH} 7.4)$ and centrifuged at $50,000 \times g$ for $20 \mathrm{~min}$ to obtain the whole particulate fraction. All fractions were washed three times by suspension in $0.2 \mathrm{~mm}$ HEPES ( $\mathrm{pH} 7.4$ ) and centrifugation at $50,000 \times \mathrm{g}$ for $20 \mathrm{~min}$ and finally resuspended in $50 \mathrm{~mm}$ HEPES ( $\mathrm{pH} 7.4)$ and stored on ice until assay (usually the following day).

Storage of membranes. Due to the length of the isolation procedure, it was necessary to store fractions for up to 2 days prior to assay. Freezing of membranes or overnight storage at $4^{\circ} \mathrm{C}$ has been shown previously to result in a large reduction of Glu binding levels (Foster and Roberts, 1978; Sharif and Roberts, 1980), and this was verified in the present study. However, we found that it was possible to store membrane fractions on ice overnight with minimal loss of binding when they were suspended in HEPES buffers. Storage in Tris

${ }^{2}$ HEPES buffers were routinely made up using $\mathrm{KOH}$, rather than $\mathrm{NaOH}$, since $\mathrm{Na}^{+}$ions are thought to enhance the binding of amino acids to sodium-dependent transport sites.

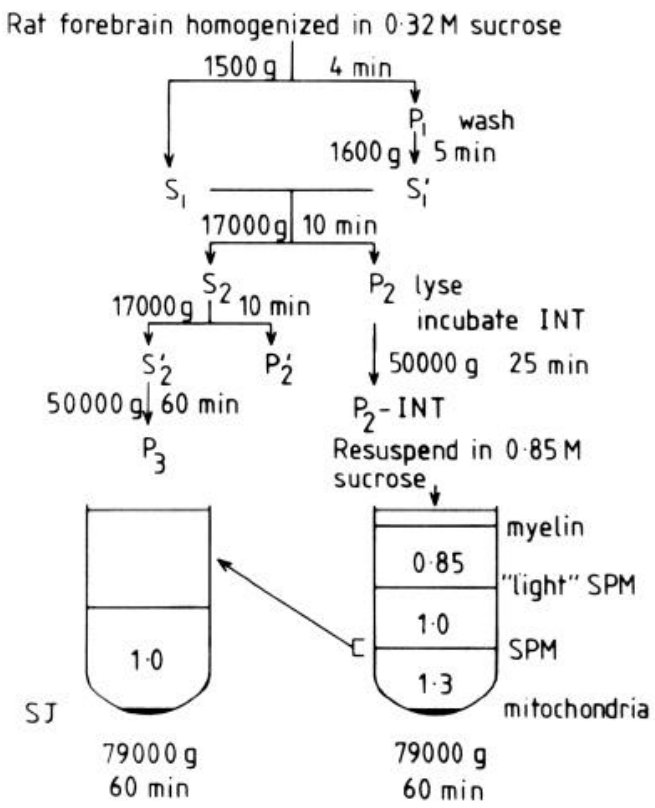

Figure 1. Flow diagram of subcellular fractionation procedure.

(tris(hydroxymethyl)aminomethane) buffer resulted in a marked loss of binding, although fractions stored in HEPES but assayed in Tris showed the same binding levels as those stored and assayed in HEPES.

Binding assays. Assays were performed essentially as described by Foster and Roberts (1978) except that the incubation conditions were optimized to $20 \mathrm{~min}$ at $30^{\circ} \mathrm{C}$ and the buffer used was $50 \mathrm{~mm}$ HEPES ( $\mathrm{pH} 7.4)$. Tissue protein was determined prior to assay by the method of Lowry et al. (1951). Whole particulate and $P_{2}$ fractions were assayed with $400 \mu \mathrm{g}$ of protein/tube, SJs at 50 to $100 \mu \mathrm{g}$ of protein/tube, and the remaining fractions at $300 \mu \mathrm{g}$ of protein/tube. The final assay volume was 1.08 $\mathrm{ml}$. With the exception of $\mathrm{P}_{3}$ membranes, assays were terminated by centrifugation for $3 \mathrm{~min}$ at $9000 \times \mathrm{g}$ in a Beckman Microfuge $B$ and the supernatant was aspirated. Greater centrifugal force was required to pellet $\mathrm{P}_{3}$ membranes, and therefore, assays were terminated by a 6 -min centrifugation at $15,000 \times g$ in a Beckman type 40.2 rotor. This procedure did not appear to alter the levels of Asp or Glu binding, as similar values were obtained for the whole particulate fraction whether assayed by the microfuge or centrifuge technique (data not shown). Membranes were solubilized and radioactivity was determined by liquid scintillation spectrometry (Beckman LS 7500).

Glu and Asp binding was assayed either separately, using the ${ }^{3} \mathrm{H}$-ligands $\left(\mathrm{L}-\left[{ }^{3} \mathrm{H}\right] \mathrm{Asp}, 9\right.$ to $15 \mathrm{Ci} / \mathrm{mmol}$; L$\left.\left[{ }^{3} \mathrm{H}\right] \mathrm{Glu}, 43.3 \mathrm{Ci} / \mathrm{mmol}\right)$, or as a double label procedure ( $\mathrm{L}-\left[{ }^{3} \mathrm{H}\right] \mathrm{Asp}, 9$ to $15 \mathrm{Ci} / \mathrm{mmol}$; L- $\left[{ }^{14} \mathrm{C}\right] \mathrm{Glu}, 282 \mathrm{mCi} / \mathrm{mmol}$ ) at a final concentration of $50 \mathrm{~nm}$ for each ligand. Nonspecific binding was determined by the inclusion of a 0.5 $\mathrm{mm}$ final concentration of unlabeled ligand in the single label assays and $0.5 \mathrm{~mm}$ Glu plus $0.5 \mathrm{~mm}$ Asp in double label assays.

The double label assay has the advantage of rapidity and conservation of membranes and, in addition, facili- 
tates a comparison between binding sites for Glu and Asp by measuring them in the same assay tube. Whether Glu and Asp bind to the same or separate sites, the following theoretical considerations indicate the validity of this procedure: (1) The labeled ligand concentration used (50 nM) is approximately 10 -fold lower than the $K_{D}$ values for both ligands (Foster and Roberts, 1978; Sharif and Roberts, 1980; Roberts et al., 1980; present study) so that, if a common site is labeled, saturation of the binding site is not achieved. (2) In previous studies, the $K_{I}$ for Asp displacement of Glu binding was found to be 6 to 20 $\mu \mathrm{M}$ (Foster and Roberts, 1978; Baudry and Lynch, 1979a). Hence, the potency of Asp is insufficient to displace Glu binding at a concentration of $50 \mathrm{~nm}$; similarly, Asp binding is not affected by $50 \mathrm{~nm}$ Glu (A. C. Foster, E. E. Mena, G. E. Fagg, and C. W. Cotman, unpublished observation). In confirmation of these arguments, preliminary experiments indicated that the levels of Glu and Asp binding measured in single label experiments were indistinguishable from those measured by the double label method, and therefore, the latter procedure was used routinely except for the $K_{D}$ determinations.

\section{Results}

Distribution of binding sites between subcellular fractions. The values for the specific binding of Glu and Asp are shown in Table I. In all fractions, the mean values of Glu binding were greater than those of Asp. This was significant in the SPM and SJ fractions ( $p<0.05 ; t$ test). There was a trend toward an increase in the specific binding of both ligands as the purity of synaptic components in each fraction increased (i.e., whole particulate $<\mathrm{P}_{2}<\mathrm{SPM}$ ). Of the $\mathrm{P}_{2}$ subfractions, lower levels of binding were found in myelin, light-SPM, and mitochondrial fractions. For Asp, the binding relative to SPMs in these latter three fractions was 51,58 , and $48 \%$, respectively, and for Glu, 13, 40, and 28\%, respectively. On further purification of myelin (Norton and Poduslo, 1973) and mitochondria (Mena et al., 1980), only low levels of binding were found in these fractions.

Purified SJs were found to possess high levels of specific binding for both ligands, some 9 -fold greater than the values in whole particulate membranes (Table I). Calculation of the total number of binding sites for individual preparations indicated that the recovery of binding sites in SJs from SPMs was $84.5 \pm 9.3 \%$ for Asp and $83.2 \pm 5.3 \%$ for Glu $(N=4)$.
Kinetics of binding to SJs. Kinetic analysis of the specific binding of Glu and Asp to SJs indicated that the binding sites were saturable, and $K_{D}$ and $B_{\max }$ values were obtained by Scatchard analysis (Fig. 2). The mean values $\left( \pm\right.$ SEM) were: Glu, $K_{D}=453 \pm 52 \mathrm{nM}$ and $B_{\max }$ $=90.74 \pm 19.3 \mathrm{pmol} / \mathrm{mg}$ of protein $(N=4) ; \mathrm{Asp}, K_{D}=$ $556 \pm 62 \mathrm{nM}$ and $B_{\max }=53.29 \pm 11.6 \mathrm{pmol} / \mathrm{mg}$ of protein $(N=5)$. The $B_{\max }$ value for Glu was significantly greater than that for Asp by paired $t$ test $(N=4 ; p<0.025)$.

Effect of ions. The effects of sodium, calcium, and magnesium ions $(100,2.5$, and $2.4 \mathrm{~mm}$, respectively, as the chloride salts) on the specific binding of both ligands were investigated in a number of subcellular fractions

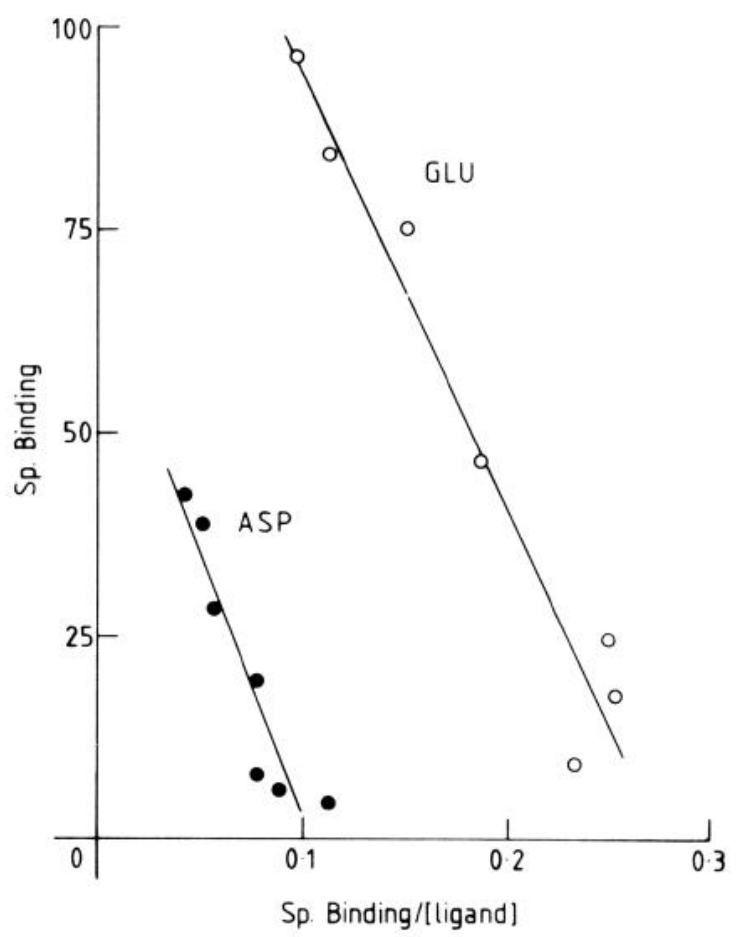

Figure 2. Typical Scatchard plot of specific Glu and Asp binding to SJs. L- $\left[{ }^{3} \mathrm{H}\right] \mathrm{Glu}$ and $\mathrm{L}-\left[{ }^{3} \mathrm{H}\right]$ Asp binding were assayed over a concentration range of 10 to $1000 \mathrm{~nm}$ as described under "Materials and Methods." Lines of best fit were determined by linear regression analysis. Ordinate, specific binding (picomoles/mg of protein); abscissa, specific binding/free ligand concentration (picomoles/mg of protein $\times \mathrm{nM}^{-1}$ ). $\bigcirc$, Glu; $\bullet$, Asp.

TABLE I

Distribution of specific Glu and Asp binding sites in subcellular fractions

Subcellular fractions were prepared and assayed as described under "Materials and Methods." Assays were performed in triplicate and values are the means $( \pm$ SEM) for the number of determinations in parentheses. The binding values relative to whole particulate membranes (WP) (designated a value of 1) are shown next to the binding values for each fraction. The abbreviations used are as defined in the text.

\begin{tabular}{|c|c|c|c|c|c|c|}
\hline & \multicolumn{3}{|c|}{ Aspartate } & \multicolumn{3}{|c|}{ Glutamate } \\
\hline & Specific Binding & Relative to WP & $(N)$ & Specific Binding & Relative to WP & $(N)$ \\
\hline & $\mathrm{pmol} / \mathrm{mg}$ protein & & & $\mathrm{pmol} / \mathrm{mg}$ protein & & \\
\hline WP & $0.648 \pm 0.197$ & 1 & (6) & $1.202 \pm 0.358$ & 1 & (6) \\
\hline $\mathrm{P}_{2}$ & $0.765 \pm 0.175$ & 1.18 & $(6)$ & $1.539 \pm 0.424$ & 1.28 & (6) \\
\hline $\mathrm{P}_{3}$ & $1.080 \pm 0.520$ & 1.67 & (3) & $1.808 \pm 0.758$ & 1.50 & (3) \\
\hline SPM & $0.954 \pm 0.120$ & 1.47 & $(8)$ & $2.860 \pm 0.468$ & 2.34 & (11) \\
\hline SJ & $5.834 \pm 1.685$ & 9.00 & $(6)$ & $11.638 \pm 1.652$ & 9.68 & (6) \\
\hline
\end{tabular}




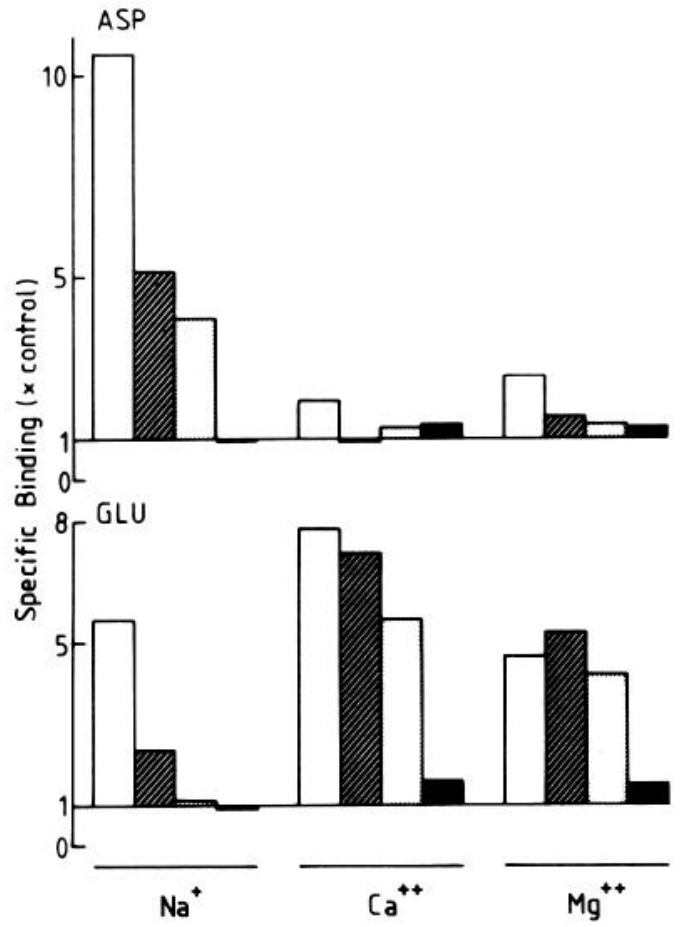

Figure 3. Effect of ions on the specific binding of Glu and Asp to different subcellular fractions. Subcellular fractions were prepared and assayed for Glu and Asp binding as described under "Materials and Methods." Assays were performed in triplicate and specific binding in the presence of ions $(\mathrm{NaCl}, 100$ $\mathrm{mM} ; \mathrm{CaCl}_{2}, 2.5 \mathrm{mM} ; \mathrm{MgCl}_{2}, 2.4 \mathrm{mM}$ ) is expressed as a multiple of the binding values obtained in the absence of ions $(=1)$ for each subcellular fraction and is averaged from three separate experiments which varied by less than $10 \%$. Open bars, whole particulate; hatched bars, $\mathrm{P}_{2}$; stippled bars, SPM; solid bars, SJ.

(Fig. 3). $\mathrm{Na}^{+}$was able to stimulate the specific binding of both Glu and Asp. For both ligands, this effect was greatest in whole particulate membranes, with values 10.5 times control for Asp and 5.5 times control for Glu. This stimulation decreased progressively through the subcellular fractions in the order, whole particulate $>\mathrm{P}_{2}$ > SPM, and was completely absent in SJs.

The divalent ions also were able to increase the binding of both ligands. In whole particulate membranes, $\mathrm{Ca}^{2+}$ increased specific Glu binding to 7.8 times control levels and Asp binding to 1.9 times control. In the same fraction, $\mathrm{Mg}^{2+}$ increased Asp binding to 2.5 times control and Glu binding to 4.6 times control. For both ions, the stimulation of Glu and Asp binding showed either little change or decreased slightly from whole particulate to $\mathrm{P}_{2}$ to SPMs. In SJs, the effect was small, and only a low proportion of the ion-stimulated binding sites in SPMs were recovered in SJs. In the case of $\mathrm{Ca}^{2+}$-stimulated Glu sites, only $10.3 \pm 4.8 \%(N=3)$ of the sites present in SPMs were retained in SJs.

The data in Figure 3 indicate that the mono- and divalent cations have differential effects on Glu and Asp binding. $\mathrm{Na}^{+}$was able to elicit a greater stimulation of Asp binding than that of Glu, this being significant in $\mathrm{P}_{2}$ and SPMs (paired $t$ test; $p<0.05 ; N=3$ ). Conversely, $\mathrm{Ca}^{2+}$ and $\mathrm{Mg}^{2+}$ were able to stimulate Glu binding to a greater extent than that of Asp in all subcellular fractions for $\mathrm{Ca}^{2+}$ and in SPMs for $\mathrm{Mg}^{2+}$ (paired $t$ test; $p<0.05 ; N$ $=3$ ).

\section{Discussion}

The major finding of this paper is the presence of high levels of specific binding sites for Glu and Asp in SJs. The 9-fold enrichment of both Glu and Asp binding in this fraction relative to whole particulate membranes appears to be due to an increase in the number of binding sites since the $K_{D}$ values for binding of the two ligands are the same as those reported for crude synaptic membranes (Foster and Roberts, 1978; Baudry and Lynch, 1979a; Sharif and Roberts, 1980; Roberts et al., 1980) and in $\mathrm{P}_{2}$ and SPM fractions (A. C. Foster, E. E. Mena, G. E. Fagg, and C. W. Cotman, unpublished observations). This indicates that the increase in binding is not due to a change in affinity of the binding site caused, for example, by the removal of an endogenous inhibitor.

The majority of binding sites in SPMs appear to be junctional, as the recovery of binding sites in SJs for both Glu and Asp is approximately $80 \%$. This is consistent with findings in locust and crayfish muscle, where extra-junctional receptors have been found to exist only in low concentration (Cull-Candy, 1978; Onedera and Takeuchi, 1980). Specific Glu and Asp binding sites were found in microsomal and light-SPM fractions, which may indicate the presence of extra-junctional receptors. However, membranes can be isolated from these fractions whose polypeptide composition is indistinguishable from SJs, indicating that some of the Glu and Asp binding in these fractions may be junctional (E. E. Mena, A. C. Foster, G. E. Fagg, and C. W. Cotman, manuscript in preparation). Thus, it is not possible in the present experiments to assess the numbers of extra-junctional receptors accurately. Despite the high levels of specific binding for Glu and Asp observed in SJs, it is clear that binding sites are present also on other subcellular particles from the small enrichment of Glu and Asp binding obtained in $\mathrm{P}_{2}$ and SPM fractions (compared to whole particulate membranes). This suggests that, in order to study binding sites for Glu and Asp that are relevant to synaptic processes, it is necessary to use a purified synaptic membrane fraction.

Recent evidence suggests that Glu binding can be regulated by different ions. In the presence of physiological $\mathrm{Na}^{+}$concentrations, Glu has been proposed to bind predominantly to membrane transport sites (Roberts, 1974; Baudry and Lynch, 1979a; Vincent and McGeer, 1980). The stimulation of Glu and Asp binding by $\mathrm{Na}^{+}$ was greatest in whole particulate membranes, decreased in SPMs, and absent in SJs, which suggests that, if uptake sites are labeled in the presence of $\mathrm{Na}^{+}$, they do not have a specific synaptic localization.

$\mathrm{Ca}^{2+}$ has been shown to cause an increase in Glu binding (Michaelis et al., 1974) by an increase in the number of binding sites with no change in affinity (Baudry and Lynch, 1979b). It might be expected that $\mathrm{Ca}^{2+}$ stimulation is a characteristic of junctional Glu sites in view of the critical role of $\mathrm{Ca}^{2+}$ in synaptic events. The extent of the $\mathrm{Ca}^{2+}$ stimulation of Glu binding was similar in whole particulate, $\mathrm{P}_{2}$, and SPM fractions, suggesting 
that $\mathrm{Ca}^{2+}$-stimulated sites are present in, but not specific for, synaptic membranes. However, the effect of $\mathrm{Ca}^{2+}$ was much reduced in SJs. One explanation for this finding is that calmodulin has been shown to be present in isolated postsynaptic densities (Grab et al., 1979), and therefore, it is possible that $\mathrm{Ca}^{2+}$ is tightly bound to the junctional region. Consequently, Glu binding sites may already be exposed to a high "endogenous" $\mathrm{Ca}^{2+}$ concentration so that the addition of further $\mathrm{Ca}^{2+}$ is not able to cause a stimulation. However, incubation of SJs with EGTA (ethylene glycol bis( $\beta$-aminoethyl ether) $N, N, N^{\prime}, N^{\prime}$ tetra-acetic acid) to remove $\mathrm{Ca}^{2+}$, followed by thorough washing, resulted in a small decrease of Glu binding but no greater stimulation by $\mathrm{Ca}^{2+}$ than in untreated membranes (A. C. Foster, E. E. Mena, G. E. Fagg, and C. W. Cotman, unpublished observation). An alternative explanation is that Triton treatment of SPMs solubilizes a membrane component which mediates the $\mathrm{Ca}^{2+}$ effect. In relation to this, it is interesting that a Glu binding protein has been solubilized from rat brain synaptic membranes by Triton treatment (Michaelis, 1975), and this retains its $\mathrm{Ca}^{2+}$ sensitivity (Grubbs and Michaelis, 1980).

The effects of the ions differentiate between the binding sites for Glu and Asp. $\mathrm{Na}^{+}$is able to cause a greater stimulation of Asp than Glu binding, whereas the converse is true for $\mathrm{Ca}^{2+}$ and $\mathrm{Mg}^{2+}$. This suggests that Glu and Asp binding sites are distinct from each other (A. C. Foster, G. E. Fagg, E. E. Mena, and C. W. Cotman, manuscript in preparation).

In summary, purified SJs from rat forebrain have been shown to possess a high density of Glu and Asp binding sites. On the basis of pharmacological studies (Foster and Roberts, 1978; Roberts et al., 1980) and recent correlations of synaptic pharmacology and binding data (Fagg et al., 1981), it is likely that these binding sites represent physiological acidic amino acid receptors. The synaptic localization of the binding sites that we have observed is that which would be expected of a transmitter receptor and suggests that Glu and Asp receptors are involved in synaptic transmission in the mammalian CNS. Further investigation of acidic amino acid binding sites in purified synaptic membrane fractions and SJs will give more information as to the characteristics of these receptors.

\section{References}

Baudry, M., and G. Lynch (1979a) Two glutamate binding sites in rat hippocampal membranes. Eur. J. Pharmacol. 57: 283285.

Baudry, M., and G. Lynch (1979b) Regulation of glutamate receptors by cations. Nature 282: 749-750.

Biziere, K., H. Thompson, and J. T. Coyle (1980) Characterization of specific, high-affinity binding sites for $\mathrm{L}-\left[{ }^{3} \mathrm{H}\right]$-glutamic acid in rat brain membranes. Brain Res. 183: 421-423.

Cohen, R. S., F. Blomberg, K. Berzins, and P. Seikevitz (1975) Structure of postsynaptic densities isolated from dog cerebral cortex. I. Overall morphology and protein composition. J. Cell Biol. 74: 181-203.

Cotman, C. W., and P. T. Kelly (1980) Macromolecular architecture of CNS synapses. In The Cell Surface and Neuronal Function, C. W. Cotman, G. Poste, and G. L. Nicholson, eds., pp. 505-533, Elsevier/North-Holland Biomedical Press, New York.

Cotman, C. W., and J. V. Nadler (1981) Glutamate and aspartate as hippocampal transmitters: Biochemical and pharma- cological evidence. In Glutamate, P. J. Roberts, J. StormMathisen, and G. A. R. Johnston, eds., John Wiley, New York, in press.

Cotman, C. W., and D. Taylor (1972) Isolation and structural studies on synaptic complexes from rat brain. J. Cell Biol. 55: 696-711.

Cull-Candy, S. G. (1978) Glutamate sensitivity and distribution of receptors along normal and denervated locust muscle fibres. J. Physiol. (Lond.) 276: 165-181.

Cull-Candy, S. G., and P. N. R. Usherwood (1973) Two populations of L-glutamate receptors on locust muscle fibres. Nature New Biol. 246: 62-64.

Curtis, D. R., and G. A. R. Johnston (1974) Amino acid transmitters in the mammalian CNS. Ergeb. Physiol. Biol. Chem. Exp. Pharmakol. 69: 97-188.

Davis, G. A., and F. E. Bloom (1973) Isolation of synaptic junction complexes from rat brain. Brain Res. 62: 135-153.

De Robertis, E., and S. Fiszer de Plazas (1976) Isolation of hydrophobic proteins binding amino acids. Stereoselectivity of the binding of $\mathrm{L}-\left[{ }^{14} \mathrm{C}\right]$-glutamate in cerebral cortex. $J$. Neurochem. 26: 1237-1243.

Fagg, G. E., and J. D. Lane (1979) The uptake and release of putative amino acid transmitters. Neuroscience 4: 1015-1036.

Fagg, G. E., A. C. Foster, E. E. Mena, J. F. Koerner, and C. W. Cotman (1981) Calcium ions and the pharmacology of acidic amino acid receptor sites. Trans. Am. Soc. Neurochem. 12 122.

Fiszer de Plazas, S., and E. De Robertis (1976) Isolation of hydrophobic proteins binding amino acids. L-Aspartic acid binding-protein from the rat cerebral cortex. J. Neurochem. 27: 889-894.

Foster, A. C., and P. J. Roberts (1978) High-affinity L- $\left[{ }^{3} \mathrm{H}\right]$ glutamate binding to postsynaptic receptor sites on rat cerebellar membranes. J. Neurochem. 31: 1467-1477.

Foster, A. C., E. E. Mena, D. T. Monaghan, and C. W. Cotman (1981) A synaptic localization of kainic acid binding sites. Nature 289: 73-75.

Grab, D. J., K. Berzins, R. S. Cohen, and P. Seikevitz (1979) Presence of calmodulin in postsynaptic densities isolated from canine cerebral cortex. J. Biol. Chem. 254: 8690-8696.

Grubbs, R. D., and E. K. Michaelis (1980) Characterization of the glutamate receptor-like protein reconstituted into liposomes. Soc. Neurosci. Abstr. 6: 254.

Johnson, J. L. (1978) The excitant amino acids glutamic and aspartic acid as transmitter candidates in the vertebrate CNS. Prog. Neurobiol. 10: 155-202.

Lowry, O. H., N. J. Rosebrough, A. L. Farr, and R. J. Randall (1951) Protein measurements with the Folin phenol reagent. J. Biol. Chem. 193: 265-275.

Mena, E. E., C. A. Hoeser, and B. W. Moore (1980) An improved method of preparing rat brain synaptic membranes. Elimination of a contaminating membrane containing $2^{\prime}, 3^{\prime}$-cyclic nucleotide- $3^{\prime}$-phosphohydrolase activity. Brain Res. 188: 207-231.

Michaelis, E. K. (1975) Partial purification and characterization of a glutamate binding membrane glycoprotein from rat brain. Biochem. Biophys. Res. Commun. 65: 1004-1012.

Michaelis, E. K., M. L. Michaelis, and L. L. Boyarsky (1974) High-affinity glutamate binding to brain synaptic membranes. Biochim. Biophys. Acta 367: 338-348.

Norton, W. T., and S. E. Poduslo (1973) Myelination in rat brain: A method of myelin isolation. J. Neurochem. 21: 749757.

Onedera, K., and A. Takeuchi (1980) Distribution and pharmacological properties of synaptic and extra-synaptic glutamate receptors on crayfish muscle. J. Physiol. (Lond.) 306: 233-250.

Roberts, P. J. (1974) Glutamate receptors in the rat CNS. Nature 252: $399-401$. 
Roberts, P. J., N. A. Sharif, and J. C. Swait (1980) Characteristics of $\mathrm{L}-\left[{ }^{3} \mathrm{H}\right]$-aspartate binding to cerebellar synaptic membranes. Br. J. Pharmacol. 70: 146P.

Sharif, N. A., and P. J. Roberts (1980) Problems associated with the binding of L-glutamic acid to synaptic membranes: Methodological aspects. J. Neurochem. 34: 779-784.

Snyder, S. H., A. B. Young, J. P. Bennett, and A. H. Mulder (1973) Synaptic biochemistry of amino acids. Fed. Proc. 32: 2039-2047.

Takeuchi, A., and K. Onedera (1975) Effects of kainic acid on the glutamate receptors of crayfish muscle. Neuropharmacology 14: 619-625.

Takeuchi, A., and N. Takeuchi (1964) The effect on crayfish muscle of iontophoretically-applied glutamate. J. Physiol. (Lond.) 170: 296-317.

Usherwood, P. N. R. (1978) Amino acids as neurotransmitters Adv. Comp. Physiol. Biochem. 7: 227-309.

Usherwood, P. N. R., and P. Machili (1968) Pharmacologica properties of excitatory neuromuscular synapses in the locust. J. Exp. Biol. 49: 349-361.

Vincent, S. R., and E. G. McGeer (1980) A comparison of sodium-dependent glutamate binding with high-affinity glutamate uptake in rat striatum. Brain Res. 184: 99-108.

Watkins, J. C. (1978) Excitatory amino acids. In Kainic Acid as a Tool in Neurobiology, E. G. McGeer, P. L. McGeer, and J. W. Olney, eds., pp. 37-69, Raven Press, New York. 